\title{
28 Research Suare \\ The Effect of Heat Treatment on Fracture Behavior in ENiCrFe-7 Weld Overlay Cladding Materials
}

Peiliang Guo ( $\square$ 2673689482@qq.com )

University of Science and Technology Beijing

H.G. Han

Unverisity of Science and Technology Beijing

Original Article

Keywords: interdendrite, precipitates, ductility, brittle, transgranular

Posted Date: August 11th, 2021

DOl: https://doi.org/10.21203/rs.3.rs-769960/v1

License: (9) This work is licensed under a Creative Commons Attribution 4.0 International License.

Read Full License 


\section{Abstract}

The effect of heat treatment (as-weld, $615^{\circ} \mathrm{C} / 48 \mathrm{~h}$ ) on fracture behavior in ENiCrFe-7 weld overlay cladding material was investigated. There were more $\mathrm{NbC}$ precipitates in the interdendrites for the heat treatment one after $615^{\circ} \mathrm{C} / 48 \mathrm{~h}$ than that of as-weld, which resulted in the lattice distortion in the interdendrites reduced by the heat treatment. As a result, the fractography was classified as brittle and transgranular fracture and the interdendrites played a major role in the failure of as-weld Alloy ENiCrFe-7, and the fractography was ductility fracture for the heat treatment one after $615^{\circ} \mathrm{C} / 48 \mathrm{~h}$.'

\section{Introduction}

It is now well recognized that $82 / 182$ alloys have been widely used for dissimilar metal welds in the reactor coolant systems of nuclear power plants. In the past few years, the intergranular stress corrosion cracking(IGSCC) or the primary water stress corrosion cracking(PWSCC) had been often discovered in these dissimilar metal weld joints ${ }^{[1]}$. It was reported that Alloy 52 series had a low susceptibility to SCC due to its higher chromium content. Therefore, alloy 52 series weld metal had been used for dissimilar weldment ${ }^{[2]}$. However, ductility dip cracking(DDC) was one of the main concerns for alloy 52 series. It was reported that DDC had been restrained by the addition of trace elements. e.g. niobium was normally added in the weldments to improve DDC and it could improve the intergranular corrosion resistance for its high carbon affinity to reduce the Cr-depletion $z^{2} \mathrm{e}^{[3,4]}$, however, it was easy to induce brittle Laves phase by which hot crack might be caused ${ }^{[5]}$. On the other hand, the hot crack can be effectively hindered by manganese. Therefore, someone adjusted manganese and niobium content and Alloy ENiCrFe-7 was ultimately made ${ }^{[6]}$.

For metallic materials, many factors have an influence on the fracture behavior, some of the most common factors are grain boundaries ${ }^{[7-8]}$, phase interfaces ${ }^{[9-10]}$, and precipitates ${ }^{[11-12]}$, etc. For Alloy ENiCrFe-7, the fracture behavior was another great concern. At present, many investigations were performed by using the macroscopic material parameters (e.g. $\left.\sigma_{U T}, A\right)^{[6,13-18]}$, comprehensive studies were often missed.

In nuclear power plants, after the dissimilar metal weld joints were welded, the heat treatment was usually performed to eliminate residual stress. However, The related literatures ${ }^{[19]}$ showed that the heat treatment temperature was usually $610 \sim 620^{\circ} \mathrm{C}$. When the heat treatment time exceeded $48 \mathrm{~h}$, the performance of the weld joint would be deteriorated ${ }^{[20]}$.

The microstructure of ENiCrFe-7 weld overlay cladding materials consists of grain boundaries, dendrites, interdendrites and precipitates. There was a correlation between microstructure and fracture behavior which was rarely reported. In this paper, the as-weld sample and one after heat treatment at $615^{\circ} \mathrm{C}$ for $48 \mathrm{~h}$ were selected for comparative study. Fracture behavior of Alloy ENiCrFe-7 with as-weld and the heat treatment one after $\left(615^{\circ} \mathrm{C} / 48 \mathrm{~h}\right)$ was studied comprehensively. 


\section{Material And Methods}

The chemical composition of Alloy ENiCrFe-7 in this study was listed in Table.1.

Table 1 Chemical composition of Alloy ENiCrFe-7 (wt\%)

\begin{tabular}{|llllllllll|}
\hline & $\mathbf{C}$ & $\mathrm{Si}$ & $\mathrm{Al}$ & $\mathrm{Ti}$ & $\mathrm{Cr}$ & $\mathrm{Mn}$ & $\mathrm{Fe}$ & $\mathrm{Nb}$ & $\mathrm{Ni}$ \\
\hline ENiCrFe-7 & 0.02 & 0.59 & 0.12 & 0.27 & 28.90 & 3.79 & 10.15 & 1.84 & Bal. \\
\hline
\end{tabular}

Several layers of Alloy ENiCrFe-7 overlay cladding material were covered on the steel surface by SMAW (Shielded Metal Arc Welding) to obtain cladding plates. Every interpass was welded not until the temperature of covered metal was governed to be below than $225^{\circ} \mathrm{C}$. The relevant welding parameters were listed in Table.2.

Table 2 Welding parameters

\begin{tabular}{|lllll|}
\hline Voltage $(\mathrm{V})$ & Current $(\mathrm{A})$ & Speed $(\mathrm{mm} / \mathrm{min})$ & Pass number $(\mathrm{N})$ & Heat input $(\mathrm{J} / \mathrm{cm})$ \\
\hline $23 \sim 26$ & 125 & 220 & 3 & $98 \sim 111$ \\
\hline
\end{tabular}

In order to perform the heat treatment, some samples were taken after welding, the heatment temperature wer $615^{\circ} \mathrm{C}$, and the holding time were $48 \mathrm{~h}$ which were followed by furnance cooling at $300^{\circ} \mathrm{C}$, and then cooling in the air.

The samples which were used for microstructure, XRD, tensile and mechanical properties test were cut from the top layers of cladding alloy as showed in Fig. 1(a) by wire-cutting. For microstructure and XRD, the dimension of sample was $10 \times 15 \times 2 \mathrm{~mm}$, for tensile test, an artifical notch was prepared on the edge of the specimen (in the central zone), and for mechanical properties, the dog bone shaped was prepared as shown in Fig. 1(b). The geometrical dimension of tensile and mechanical properties test specimen were shown in Fig. 1(c)-(d), respectively. The phase of Alloy ENiCrFe-7 was analyzed by X-ray diffractometry (XRD, PANalytical B.V, Holland) with Cu Ka radiation operated at the voltage of $45 \mathrm{kV}$ and current of $45 \mathrm{~mA}$. And the tensile curve was performed on VL2000DX - SVF17SP equipment with a strain rate of $10^{-3} S^{-1}$.

The detailed schematic of tensile device was shown in Fig. 2. The device was made up of three parts (A, $B$ and $C$ ), the $B$ part was moved by the rotation of the middle screw thread. The degree of deformation on the test sample can be controlled by rotation the angle of screw thread. These test samples were gradually ground to 5000 \# grit with Si-C papers, and then polished using a $2.5 \mu \mathrm{m}$ diamond paste. In order to observe microstructure and the surface morphology of deforming materials, the samples were etched at $10 \mathrm{~V}$ in a solution of $4 \mathrm{Vol} \% \mathrm{H}_{2} \mathrm{SO}_{4}$ before tensile test. In-situ and ex-situ observation was performed on 
the surface of deforming materials by SEM during tensile test. Finally, the fractography was performed to uncover fracture mechanism.

\section{Result And Discussion}

Fig. 3 shows SEM image of the as-weld Alloy ENiCrFe-7 and the heat treatment one after $615^{\circ} \mathrm{C} / 48 \mathrm{~h}$, it is found that Alloy ENiCrFe-7 consists of dendrite(No.1), interdendrite(No.2), spherical precipitates(No.3) in the dendrites and irregular precipitates(No.4) in the interdendrites. It is revealed from Table.3 that $\mathrm{Nb}$ content of interdendrites is higher than that of dendrite, it is caused by constitutional supercooling and the equilibrium partition coefficient $\mathrm{K}$ of $\mathrm{Nb}$ is less than $1^{[21]}$, it is also found that the precipitates are $(\mathrm{Al}, \mathrm{Ti}, \mathrm{O})$-rich in the dendrite and $(\mathrm{Nb}, \mathrm{C})$-rich in the interdendritic region simultaneously. There are not precipitates at the grain boundary of the as-weld alloy ENiCrFe-7, while heat treatment one after 48h have continuous precipitates along the grain boundary.

Table 3 Element compositions of each phases in Fig. 3 analyzed by EDS on SEM (wt\%).

\begin{tabular}{|lllllllllll|}
\hline Phase in Fig. 3 & $\mathbf{O}$ & $\mathbf{A l}$ & $\mathbf{S i}$ & $\mathbf{C}$ & $\mathrm{Ti}$ & $\mathbf{C r}$ & $\mathrm{Mn}$ & $\mathrm{Fe}$ & $\mathbf{N i}$ & $\mathbf{N b}$ \\
\hline 1 & - & - & 0.6 & 4.7 & - & 30.4 & 3.4 & 11.6 & 52.6 & 1.4 \\
\hline 2 & - & - & 1.4 & 3.9 & - & 26.8 & 4.8 & 9.4 & 50.1 & 3.8 \\
\hline 3 & 39.7 & 33.3 & - & - & 9.5 & 6.6 & 1.1 & 1.8 & 7.9 & - \\
\hline 4 & - & - & 3.9 & 8.8 & - & 16.8 & 4.5 & 4.8 & 42.6 & 27.3 \\
\hline
\end{tabular}

Figure 4 is the BSE image of the as-weld Alloy ENiCrFe-7 and the heat treatment one after $615^{\circ} \mathrm{C} / 48 \mathrm{~h}$. It can be seen from Fig. 4 that Alloy ENiCrFe-7 is mainly composed of black, white, gray-white and grayblack phases. According to Table.4, it can be seen that the black phase (No.1) is (Al,Ti,O) compounds, and the white phase $(\mathrm{No} .2)$ is $(\mathrm{Nb}, \mathrm{C})$-rich phase. According to related literature ${ }^{[22]},(\mathrm{Al}, \mathrm{Ti}, \mathrm{O})$ compound and $(\mathrm{Nb}, \mathrm{C})$-rich are $\mathrm{Al}_{2} \mathrm{O}_{3}$ and $\mathrm{NbC}$, repectively. The gray-white phase (No.3) has a higher $\mathrm{Nb}$ content, so it is interdendrite, and the gray-black phase (No.4) is dendrite, which is consistent with the results in Fig. 3. It can be seen from Fig. 4 (c) that the number of $\mathrm{NbC}$ in the heat treatment $\left(615^{\circ} \mathrm{C} / 48 \mathrm{~h}\right)$ alloy is more than that of as-weld, while the effect of heat treatment on the number of $\mathrm{Al}_{2} \mathrm{O}_{3}$ precipitates is not obvious.

Table 4 Element compositions of various phases in Fig. 4 by BSE-EDS(wt. \%) 


\begin{tabular}{|lllllllllll|}
\hline Phase in Fig. 4 & $\mathrm{C}$ & $\mathrm{Si}$ & $\mathrm{Ti}$ & $\mathrm{Nb}$ & $\mathrm{Mn}$ & $\mathrm{Fe}$ & $\mathrm{Al}$ & $\mathbf{0}$ & $\mathrm{Cr}$ & $\mathrm{Ni}$ \\
\hline 1 & - & 1.5 & 7.4 & 0.1 & - & 0.7 & 46.0 & 40.0 & 2.9 & Bal. \\
2 & 13.1 & 1.1 & 2.2 & 39.7 & 2.3 & 4.5 & - & - & 15.1 & Bal. \\
3 & - & 1.6 & - & 3.9 & 4.8 & 8.9 & - & - & 27.7 & Bal. \\
4 & - & 0.6 & - & 0.3 & 3.6 & 9.5 & - & - & 28.8 & Bal. \\
\hline
\end{tabular}

It is found from Fig. 5(a) that the characteristic peaks of Alloy ENiCrFe-7 including as-weld alloy and that of $615^{\circ} \mathrm{C} / 48 \mathrm{~h}$ are single phase, it is slightly different from the standard fcc $2.90 \mathrm{Ni0} .70 \mathrm{Cr} 0.36 \mathrm{Fe}$ austenitic phase as shown in black line, which resulted from lattice distortion of that austenite ${ }^{[23]}$. It is believed that $\mathrm{Nb}$ atoms are dissolved into the interdendrites of $2.90 \mathrm{Ni0} .70 \mathrm{Cr} 0.36 \mathrm{Fe}$ austenitic phase, which play an important role in the lattice deformation, it is comfirmed by H.T. Lee ${ }^{[24]}$. It can be observed from Fig. 5(b) there is smaller lattice deformation in heat treatment sample than that of as-weld alloy, which is related to the precipitation of $\mathrm{NbC}$ as shown in Fig. $4(\mathrm{C})$. The (Al,Ti,O)-rich and $(\mathrm{Nb}, \mathrm{C})$-rich phase were not found in Fig. 5, which resulted from less (Al,Ti,O)-rich compound and $(\mathrm{Nb}, \mathrm{C})$-rich phase.

Figure 7(a) and (b) are SEM image of crack initiation in the different precipitates. Combined with Fig. 7(c) and $(\mathrm{d})$, there are some microcracks observed in $(\mathrm{Al}, \mathrm{Ti}, \mathrm{O})$ compounds and $(\mathrm{Nb}, \mathrm{C})$-rich phase, this appearance is rather common in Alloy ENiCrFe7, the problem is caused by the poor ductility of precipitates that cannot sustain sufficient plastic deformation as the matrix, which resulted from both $(\mathrm{Al}, \mathrm{Ti}, \mathrm{O})$-rich ${ }^{[25]}$ and $(\mathrm{Nb}, \mathrm{C})-$ rich $^{[26]}$ belonging to hard and brittle phase.

Figure 8 shows the effect of grain boundaries on the deformation behavior of the as-weld Alloy ENiCrFe-7 and the heat treatment one after $615^{\circ} \mathrm{C} / 48 \mathrm{~h}$. It can be seen from Fig. 8 that the direction of slip lines on both the sides of grain boundary in the as-weld sample is inconsistent, which indicates that the grain boundary has a certain effect on its deformation, but there is no crack in the grain boundary of as-weld sample, it indicates that a good bonding force exist between grains in the as-weld sample. Compared with the as-weld sample, it can be seen from Fig. 8 that some micro-cracks appear along the grain boundary of sample after heat treatment for $48 \mathrm{~h}$, which indicates that the precipitates generated by the heat treatment reduce the bonding force between the grains.

Figure 9 shows the relationship between the slip lines and interdendrites after deformation in the as-weld Alloy ENiCrFe-7 and the heat treatment one after $615^{\circ} \mathrm{C} / 48 \mathrm{~h}$. It can be seen from Fig. 9 (a) that the slip line can be interrupted by the interdendrites, it indicates that the deformation behavior is inconsistent between the interdendrites and dendrites. Compared with the as-weld sample, the influence of interdendrites on the slip line in the heat treatment one after $615^{\circ} \mathrm{C} / 48 \mathrm{~h}$ is weaker under the same degree of deformation, some slip lines are not even affected by the interdendrites, it shows that the heat treatment can improve the deformation coordination between the interdendrites and dendrites. 
Figure 10 is the SEM image of the interdendritic deformation in the as-weld Alloy ENiCrFe-7 and the heat treatment one after $615^{\circ} \mathrm{C} / 48 \mathrm{~h}$. Combined with Table.5, it can be seen from Fig. 10(a) that the $\mathrm{Nb}$ content ( $2 \sim 4 \mathrm{wt} . \%)$ of sites 2 and 3 are higher than site 1, and it is consistent with the Nb content of interdendrites in Fig. 3, which indicates the sites 2 and 3 are the interdendrites. It can be seen from Fig. 10(a) that there are some microcracks in the interdendrites of the as-weld sample. Under the same extent of deformation, it can be also seen from Fig. 10(b) that the slip lines of the sample are not almost interrupted from interdendrites after heat treatment for $48 \mathrm{~h}$, and no crack appear. That is to say, compared with as-weld sample, the one after heat treatment for $48 \mathrm{~h}$ has better deformation coordination between the interdendrites and dendrites.

Table 5 Element compositions of various phases in Fig. 10 by SEM-EDS(wt. \%)

\begin{tabular}{|lllllll|}
\hline Phase in Fig. 10 & Nb & Mn & Si & Fe & Cr & Ni \\
\hline 1 & - & 4.4 & 0.8 & 11.2 & 30.8 & Bal. \\
\hline 2 & 2.3 & 4.4 & 1.0 & 10.5 & 29.5 & Bal. \\
\hline 3 & 3.9 & 5.0 & 1.4 & 9.7 & 27.9 & Bal. \\
\hline
\end{tabular}

Figure 11 is a trend of crack propagation near a notch tip of as-weld Alloy ENiCrFe-7. Combined with Table.6, it is known that No.1 is the interdendrite and it is found from Fig. 11(a) that the microcrack is formed in the phase interface between dendrite and interdendrite. It indicates that the interface is weaker position against crack. Such a microcrack can bring about significant stress concentration at the phase interface, which could decrease the local strength considerably. Moreover, because of the limited distance(about several $\mu \mathrm{m}$ ) of microcrack to the crack of notch tip, its strength can be further weakened due to stress concentration in the crack of notch tip. As a result, the concerned microcrack becomes a critical site for the main crack. The coalescence of two microcrack into the main crack is found in Fig. 11(b), it can be also remarked that the interdendritic region plays a important role in propagation of crack path due to its larger size.

Table 6 Element compositions of various phases in Fig. 11 by SEM-EDS(wt. \%)

\begin{tabular}{|lllllll|}
\hline Phase in Fig. 11 & $\mathrm{Si}$ & $\mathrm{Cr}$ & $\mathrm{Mn}$ & $\mathrm{Fe}$ & $\mathrm{Ni}$ & $\mathrm{Nb}$ \\
\hline 1 & 0.6 & 27.8 & 4.7 & 12.9 & 50.2 & 3.6 \\
2 & 0.6 & 30.4 & 3.4 & 11.8 & 54.0 & - \\
\hline
\end{tabular}


Figure 12 shows the fractography of the as-weld Alloy ENiCrFe-7 and the heat treatment at $615^{\circ} \mathrm{C}$ for $48 \mathrm{~h}$ after tensile test. It can be seen from Fig. 12(a) and (b) that the fractography of as-weld ENiCrFe-7 is composed of a number of Bluff pattern and dimples, it indicates that the fracture mode is a brittle and transgranular fracture ${ }^{[27]}$. It can be concluded from Fig. 10 and Fig. 11 that the Bluff plane originates from the interdendritic region, the same conclusion was drawn by Lee ${ }^{[24]}$ and Huang ${ }^{[28]}$. From Fig. 12(c) and (d), it can be seen that the fractography in the alloy after heat treatment for $48 \mathrm{~h}$ are composed of dimples, it indicates that the fracture mode is ductility. It is possible that the precipitation of $\mathrm{NbC}$ resulted in a reduction in the lattice distortion in the interdendrites, which reduce the stress concentration in interdendrites during fracture, as a result, there are better deformation coordination between the dendrites and interdendrites as shown in Fig. 9(b) and Fig. 10(b). Although the intergranular precipitates can reduce the bonding force between the grains as shown in Fig. 8(b), there is no intergranular cracks in the fractography of heat-treated at $615^{\circ} \mathrm{C}$ for $48 \mathrm{~h}$ sample as shown in Fig. 12 (c)-(d), it indicates that the weaker bonding force between the grains does not play a major role during the fracture. In addition, it can be aslo found from Fig. 12(b) and (d) there are precipitates in the dimples, it indicates that the precipitates contribute to the formation of dimples.

Figure 13 represents that the stress-strain curve obtained of the as-weld Alloy ENiCrFe-7 and the heat treatment one after $615^{\circ} \mathrm{C} / 48 \mathrm{~h}$ at room temperature. There are no apparent yielding plateau, then it is followed by a long work hardening stage. A typical elasto-plastic deformation behavior is observed. The elongation to failure can achieve $27.3 \%$ and $36.7 \%$, with the ultimate tensile strength about $3.17 \mathrm{kN}$ and $3.3 \mathrm{kN}$ for as-weld and heat treatment one after $48 \mathrm{~h}$ alloy, respectively. When the ultimate tensile strength of as-weld sample reaches $3.17 \mathrm{kN}$, it drops rapidly, it indicates that as-weld ENiCrFe-7 fails with brittle fracture. When the ultimate tensile strength of heat treatment one after $615^{\circ} \mathrm{C} / 48 \mathrm{~h}$ sample reaches largest, it descends in an arc, it indicates the heat treatment one after $615^{\circ} \mathrm{C} / 48 \mathrm{~h}$ sample fails with ductility fracture.

\section{Conclusions}

The effect of heat treatment (as-weld, $615^{\circ} \mathrm{C} / 48 \mathrm{~h}$ ) on fracture behavior in ENiCrFe-7 weld overlay cladding material was investigated, the following conclusions can be obtained.

1. There was no precipitate along the grain boundary of as-weld Alloy ENiCrFe-7, the heat treatment not only promoted the intergranular precipitate and interdendritic $\mathrm{NbC}$ formed, but also reduced lattice distortion.

2. The transgranular precipitates contributed to the formation of dimple.

3. The precipitates along the grain boundary can reduce the bonding force beween grains.

4. Fracture model of as-weld Alloy ENiCrFe-7 was brittle and transgranular, the interdendritic region played a major role in the failure of the material. While the fractography of heat treatment one after $615^{\circ} \mathrm{C} / 48 \mathrm{~h}$ sample was ductility.

\section{Declarations}


Availability of data and materials

All data generated or analysed during this study are included in this published article.

\section{Competing interests}

The authors declare that they have no competing interest.

\section{Funding}

Supported by the present work from Beijing Municipal Science \& Technology Commission (Z181100005218005).

\section{Authors'contributions}

PG was in charge of the whole trial and wrote the manuscript; $\mathrm{HH}$ assisted with sampling. All authors read and approved the final manuscript.

\section{Acknowledgements}

The authors sincerely thank University of science and technology Beijing for their help with the test.

\section{References}

[1] Gorman J, Hunt S, Riccardella P, et al. PWR reactor vessel alloy 600 issues. Companion Guide to the ASME Boiler \& Pressure Vessel Code, 2009, 3.

[2] Bamford W, Hall J. Cracking of alloy 600 nozzles and welds in PWRs: review of cracking events and repair service experience//12th International Conference on Environmental Degradation of Materials in Nuclear Power System-Water Reactors. 2005: 959-966.

[3] Ramirez A J, Sowards J W, Lippold J C. Improving the ductility-dip cracking resistance of Ni-base alloys. J. Mater. Process. Tech, 2006, 179(1): 212-218.

[4] Mo W, Lu S, Li D, et al. Effects of filler metal composition on inclusions and inclusion defects for ER NiCrFe-7 weldments. J. Mater. Sci. Tech, 2013, 29(5): 458-466.

[5] DuPont J N, Robino C V, Marder A R. Solidification and weldability superalloys. Weld. J, 1998.

[6] Tsungyuan Kuo, Hwa teng Lee, et al. An Evaluation of the Effects of $\mathrm{Nb}$ and Mn Addition on NickelBase Weldments. Sci. Technol. Weld. Joi, 2003,1(8):39-48.

[7] Renyao Qin, Huang Wang, et al. Investigation on the Microstructure and Ductility-Dip Cracking susceptibility of the Butt Weld Welded with ENiCrFe-7 Nickel-base Alloy-Covered Electrodes, Metall. Mater. Trans. A, 46A (2014) 1227-1236. 
[8] B.C. Kim, S. Lee, et al. In situ Fracture observations on tempered martensite embrittlement in an AISI 4340 steel. Metall. Trans. A, 22A (1991) 1889-1892.

[9] Byeongho Kim, Jeonghyeon Do, et al. In situ fracture observation and fracture toughness analysis of squeeze cast AZ51-xSn magnesium alloys. Mater. Sci. Eng. A, 527 (2010) 6745-6757.

[10] X.Y. Cao, P. Zhu, et al. An investigation on microstructure and mechanical property of thermally aged stainless steel weld overlay cladding. J. Nucl. Mater, 496 (2017) 172-182.

[11] Tae-Hyuk Lee, Ho-Young Suh, et al. Effect of a heat treatment on the precipitation behavior and tensile properties of alloy 690 steam generator tubes. J. Nucl. Mater, 479 (2016) 85-92.

[12] Y. M. He, J. G. Yang, et al. Effect of high-temperature aging on microstructure and mechanical properties of Ni-Mo-Cr based superalloy subjected to simulated heat-affected zone thermal cycle. J. Alloy. Compd, 660 (2016) 266-275.

[13] Yifeng Li, Jianqiu Wang, En-Hou Han. Characterization of ferroniobium topologically close-packed phase inclusion in nickel-based 152 cladding of dissimilar metal welds. J. Nucl. Mater, 515 (2019) 267275.

[14] Yifeng Li, Jianqiu Wang, En-Hou Han, et al. Structural, mechanical and corrosion studies of Cr-rich inclusions in 152 cladding of dissimilar metal weld joint. J. Nucl. Mater, 498 (2018) 9-19.

[15] Dinesh W. Rathod, Sunil Pandey, et al. Mechanical properties variations and comparative analysis of dissimilar metal pipe welds in pressure vessel system of nuclear plants. J. Pressure Vessel Tech, 138 (2016) 1-9.

[16] H. T. Lee, S. L. Jeng, T. Y. Kuo. The Microstructure and Fracture behavior of the dissimilar Alloy 690SUS 304L joint with various Nb addition, Metall. Trans. A, 34 (2001) 1097-2003.

[17] Yuan Hao, Ma Chengyong, et al. Influence of $\mathrm{Nb}$ on microstructure and mechanical properties of ENiCrFe-7 weld metal of 690 Ni-based alloy welding rod, Heat. Treat. Met, 42 (2017) 16-20.

[18] Yuan Hao, Ma Chengyong, et al. Research of the microstructure and properties of ENiCrFe-7 weldments, Mater. Sci. Tech, 24 (2016) 41-46.

[19] Xue Xiao-yuai, Li Zhi-yuan, Wang Zhi-ying, et al, Effect of postweld heat treatment on microstructure and properties of stainless steel surfacing layer of CAP1400 evaporator pressure boundary weld,T. Mater. Heat. Treat, 39(2018)108-112.

[20] Fan Yindong, Huang Yifang, Effect of heat treatment holding time on mechanical properties of deposited metal of low-alloy steel electrode CHE608HR for nuclear equipment, Elec. Weld. Mach, 49(2019)164-167. 
[21] Gang Li, Maolong Zhang, et al, A comparative study on microstructure and properties of Inconel 52M overlays deposited by laser beam and GTA cladding, Int. J. Adv. Manuf. Technol, 81 (2015), 103-112.

[22] P.L. Guo, L.G. Ling, Z.R. Chen, et al, Effect of heat treatment on the microstructure and corrosion resistance behavior of ENiCrFe-7 weld overlay cladding material, J. Nucl. Mater, 527(2019)151786.

[23] Xiang Xin, Chen Changan, et al, Effect of Fe and C Doping on the Lattice Distortion of He lon Implanted Al Surface by XRD, Rare. Metal. Mater. Eng, 40 (2011) 1610-1615.

[24] Lee H T, Jeng S L, Kuo T Y. The Microstructure and Fracture behavior of the dissimilar alloy 690-SUS 304L joint with various Nb addition[J]. Metall. Mater. Trans. A, 2001, 34A: 2003-1097.

[25] Murakami T, Sasaki S, Ichikawa K, et al. Oxidation resistance of powder compacts of the $\mathrm{Nb}-\mathrm{Si}-\mathrm{Cr}$ system and Nb3Si5Al2 matrix compacts prepared by spark plasma sintering, Intermetall, 9 (2001) 629635.

[26] S. L. Jeng, H. T. Lee, et al, Effects of $\mathrm{Nb}$ on the microstructure and elevated-temperature mechanical properties of Alloy 690-SUS 304L dissimilar welds, Mater. Trans, 49 (2008) 1270-1277.

[27] L. Y. Wu, K. Y. Luo, et al, Effects of laser shock peening on the micro-hardness, tensile properties, and fracture morphologies of CP-Ti alloy at different temperatures, Appl. Surf. Sci, 431 (2018) 122-134.

[28] Huang J Y, Yung T Y, Huang J S, et al. Effects of heat treatment and chromium content on the environmentally assisted cracking behavior of the dissimilar metal welds in simulated BWR coolant environments[J]. Corros. Sci, 2013, 75: 386-399.

\section{Figures}




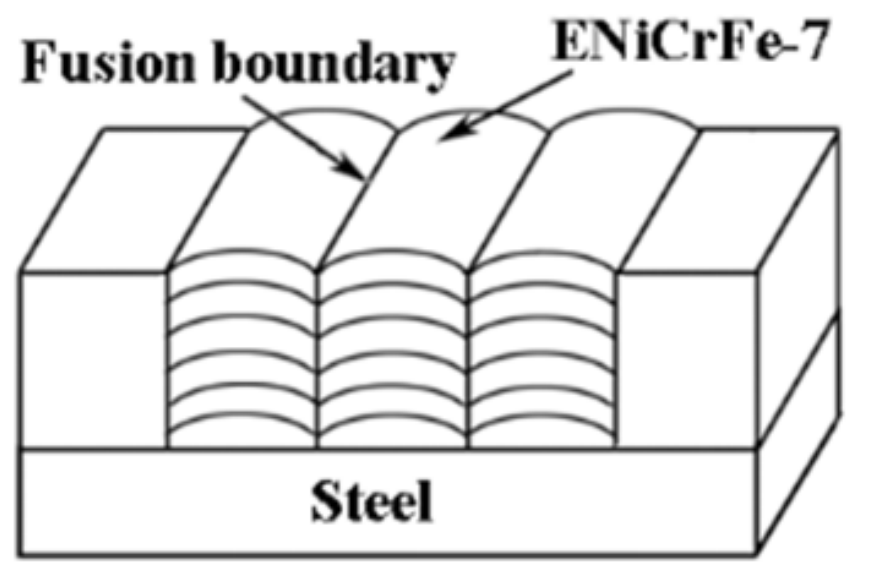

(a)
Fusion boundary

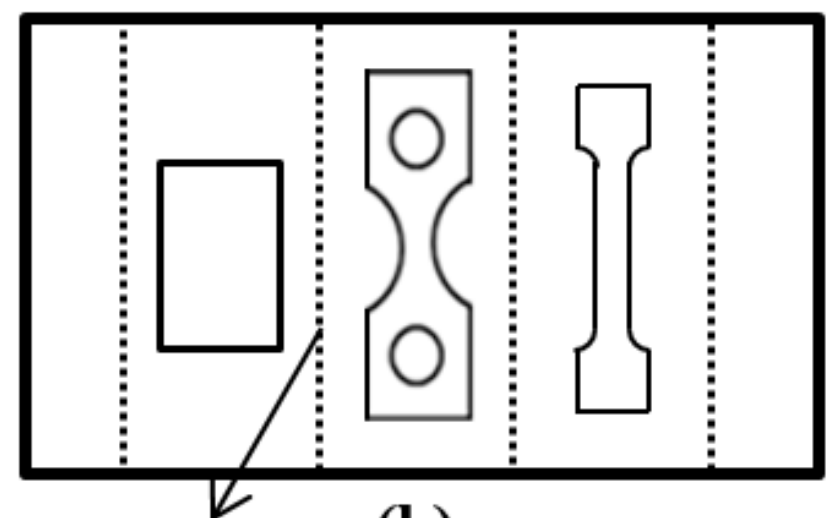

(b)

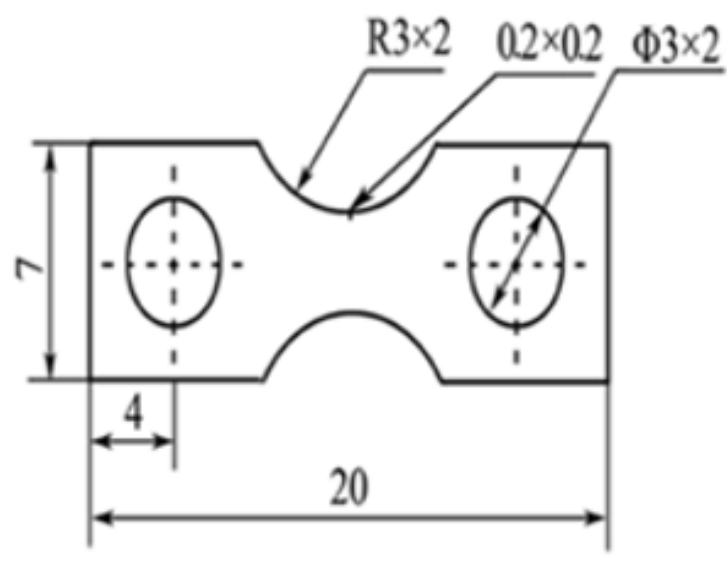

(c)

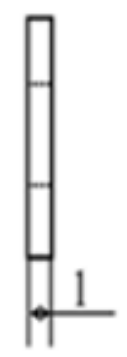

(d)

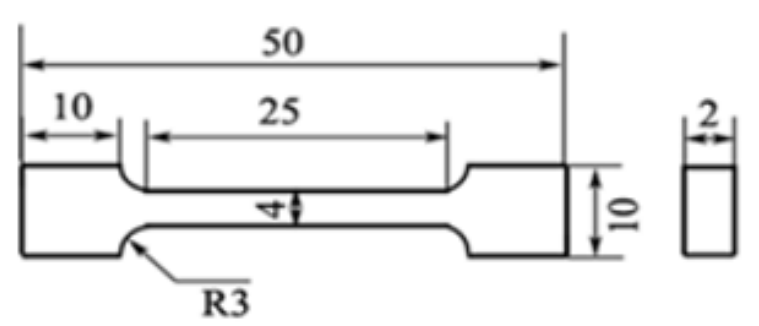

Unit:mm

Figure 1

(a) Test material schematic, (b) the location of various test specimen, (c) the dimension of tensile specimen, (d) the dimension of mechanical properties specimen. 


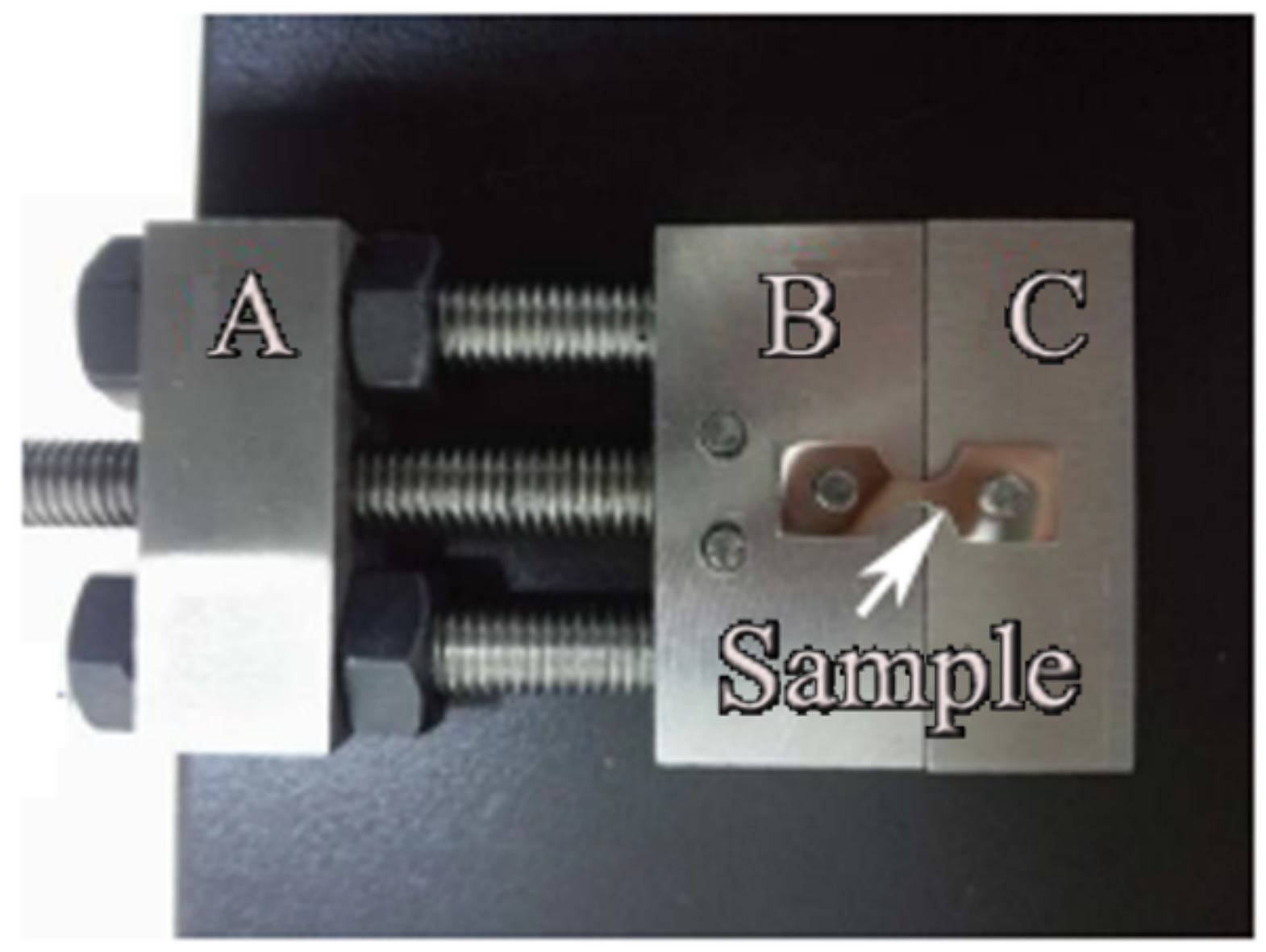

Figure 2

Schematic of tensile device
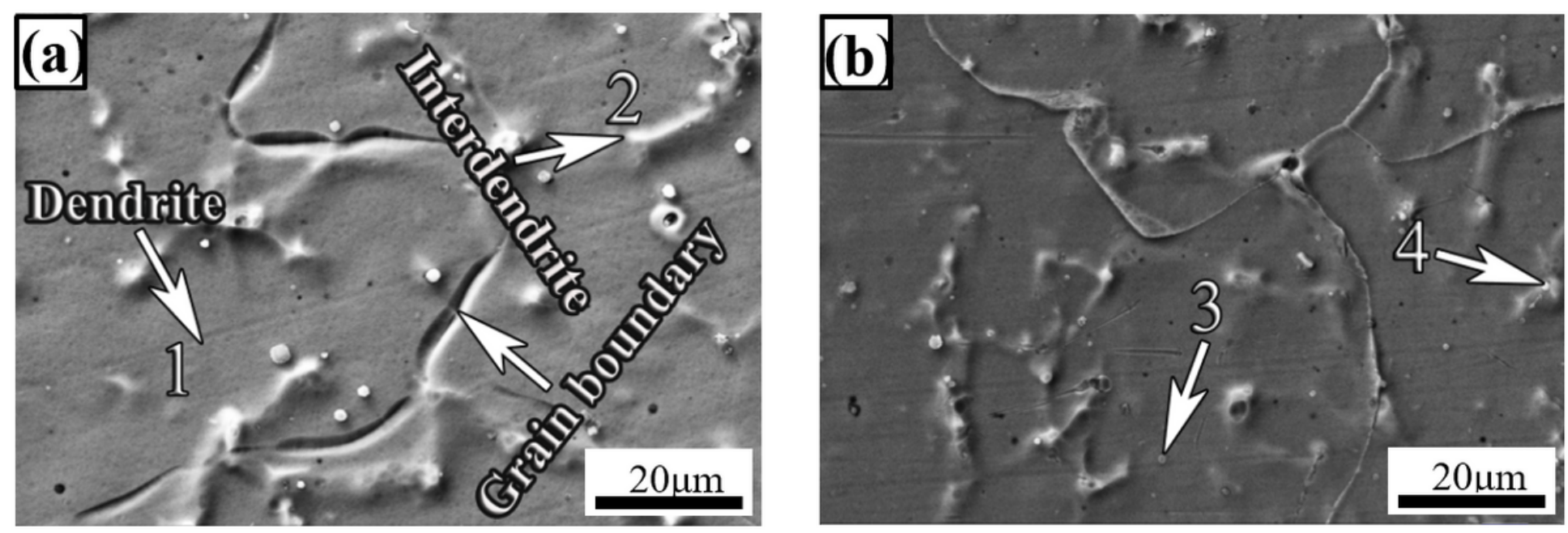

Figure 3

SEM images of ENiCrFe-7 with (a) as-weld and (b) $615^{\circ} \mathrm{C} / 48 \mathrm{~h}$. 

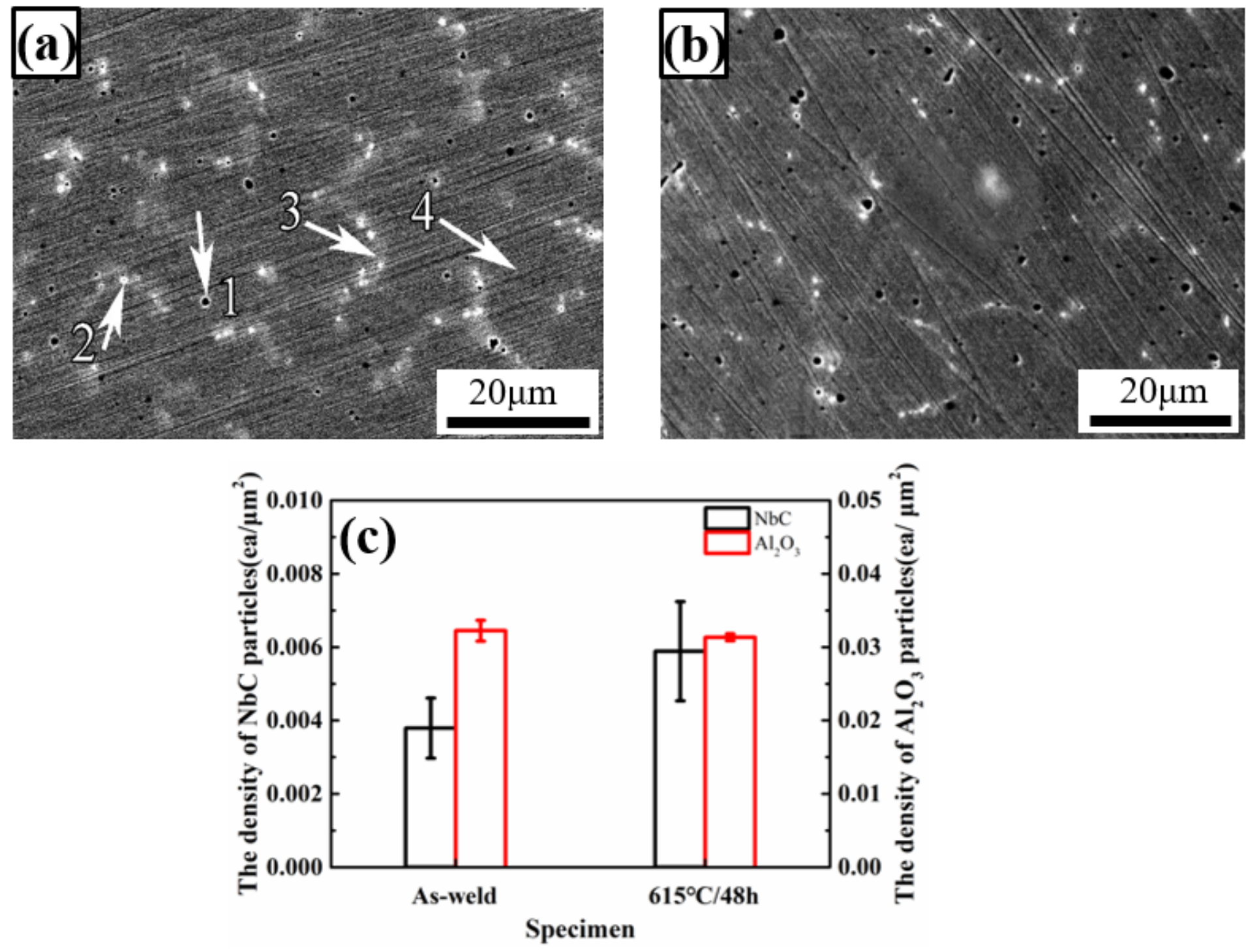

Figure 4

BSE imgaes showing microstructure (a) as-weld Alloy ENiCrFe-7 and (b) heat treatment one after $615^{\circ} \mathrm{C} / 48 \mathrm{~h}$, as well as (c) their distribution density of transgranular precipitates including NbC and Al2O3 in both alloys. 

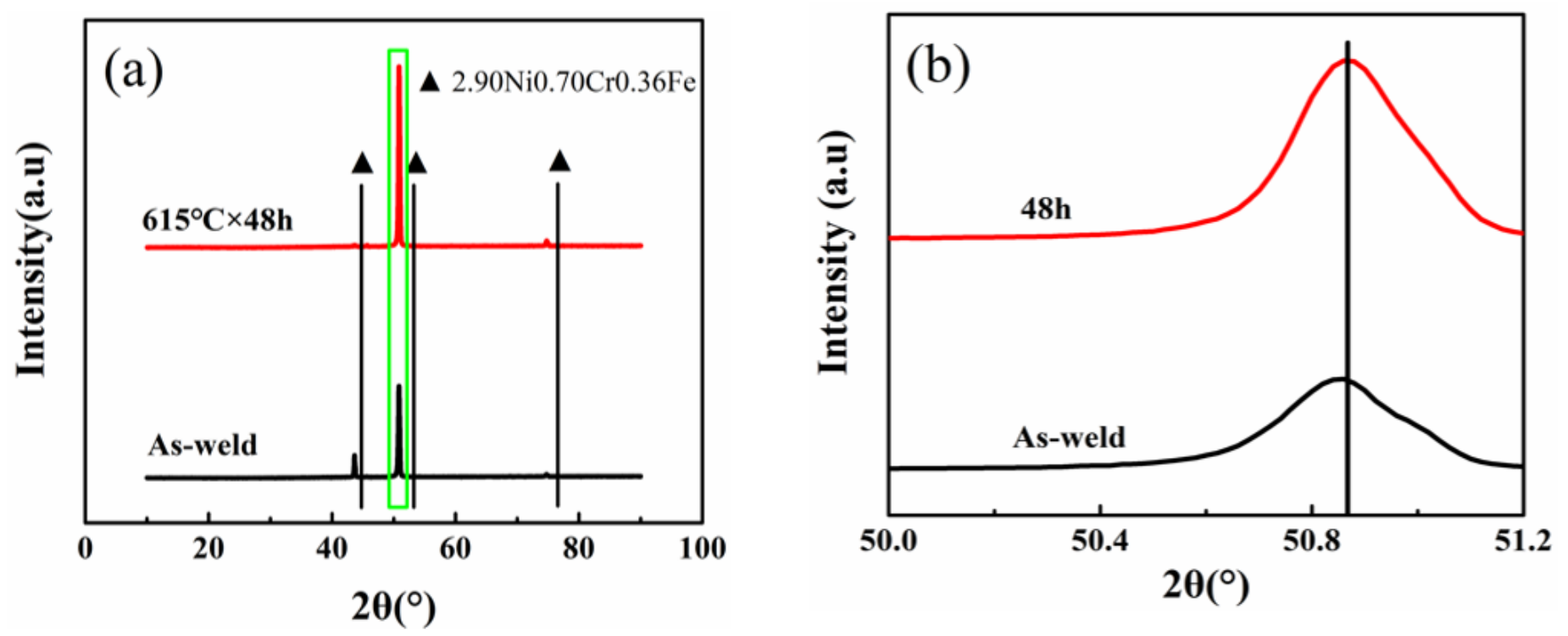

Figure 5

(a) The XRD pattern of ENiCrFe-7 including as-weld and $615^{\circ} \mathrm{C} / 48 \mathrm{~h}$ alloy, as well as (b) magnified XRD images of the rectangle region marked in (a). 

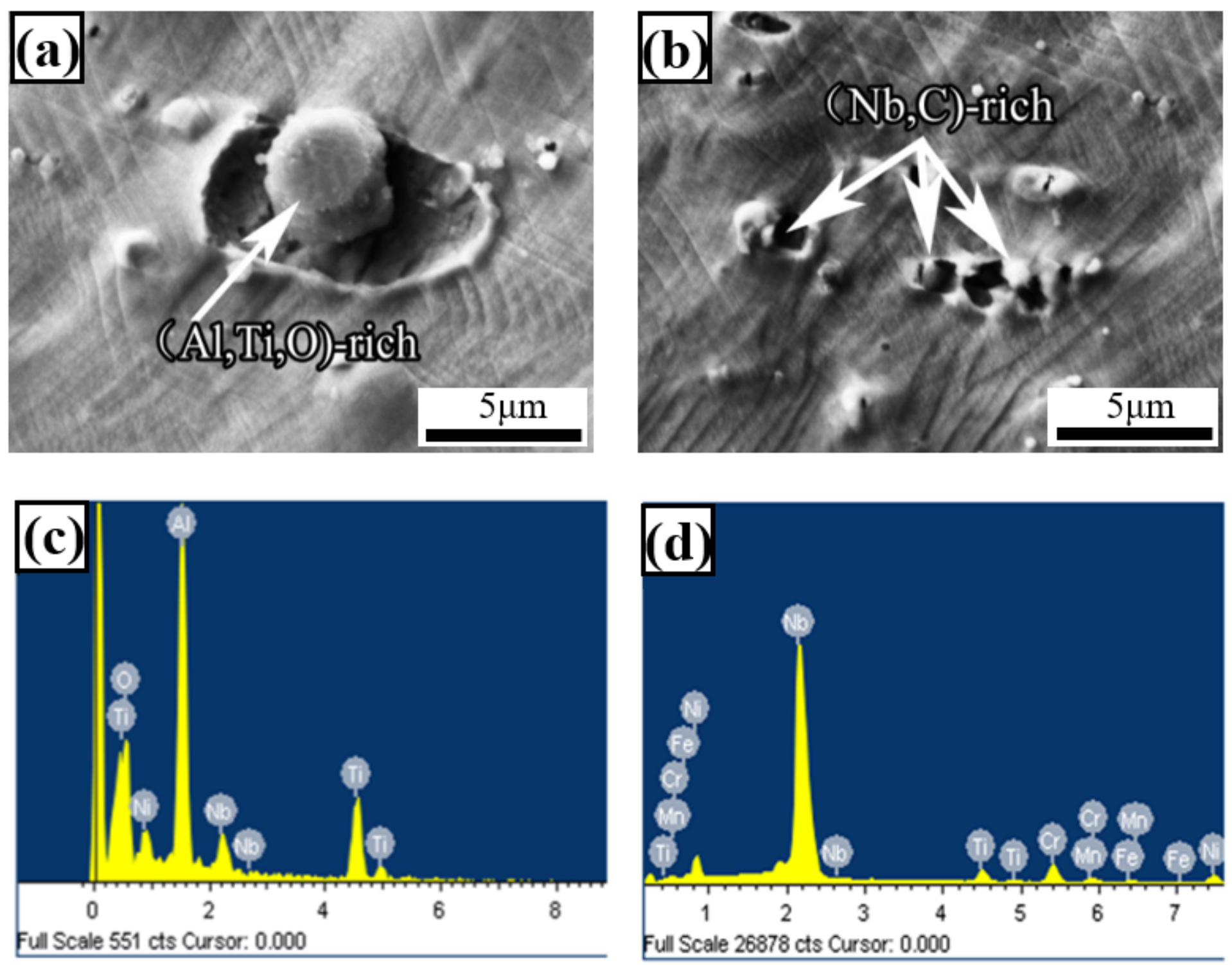

Figure 6

SEM images of the microvoid nucleation observed; (a) Al-Ti-O compound, (b) (Nb,C)-rich, as well as (c) EDS result of the precipitate in Fig.6(a) and (d) EDS result as shown in the precipitate of Fig.6(b). 

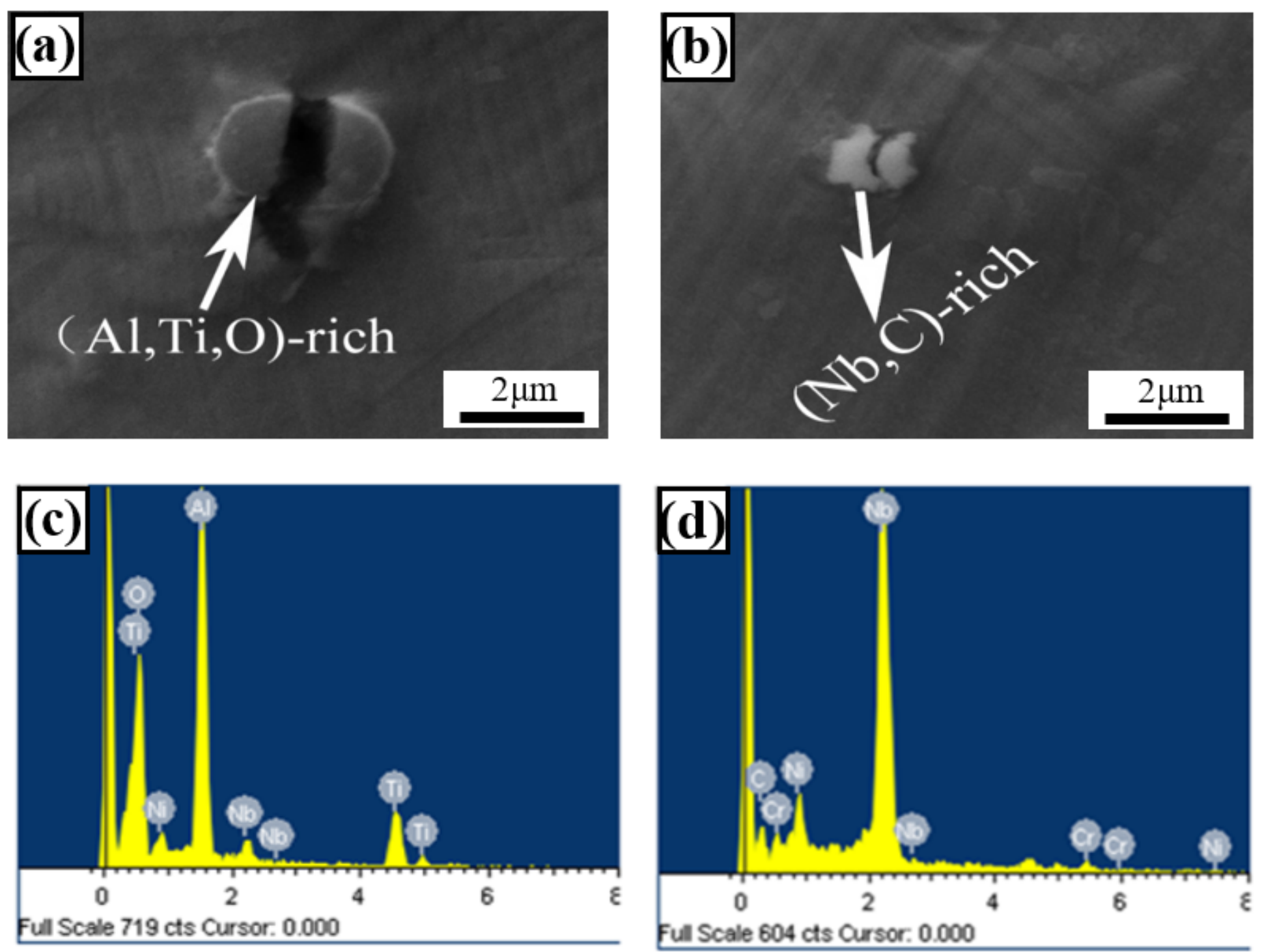

\section{Figure 7}

SEM images of the crack observated in the different precipitates; (a) crack in (Al,Ti,O)-rich, (b) crack in $(\mathrm{Nb}, \mathrm{C})$-rich, as well as (c) EDS result of the precipitate in Fig.7(a), and EDS result of the precipitate in Fig.7(b). 


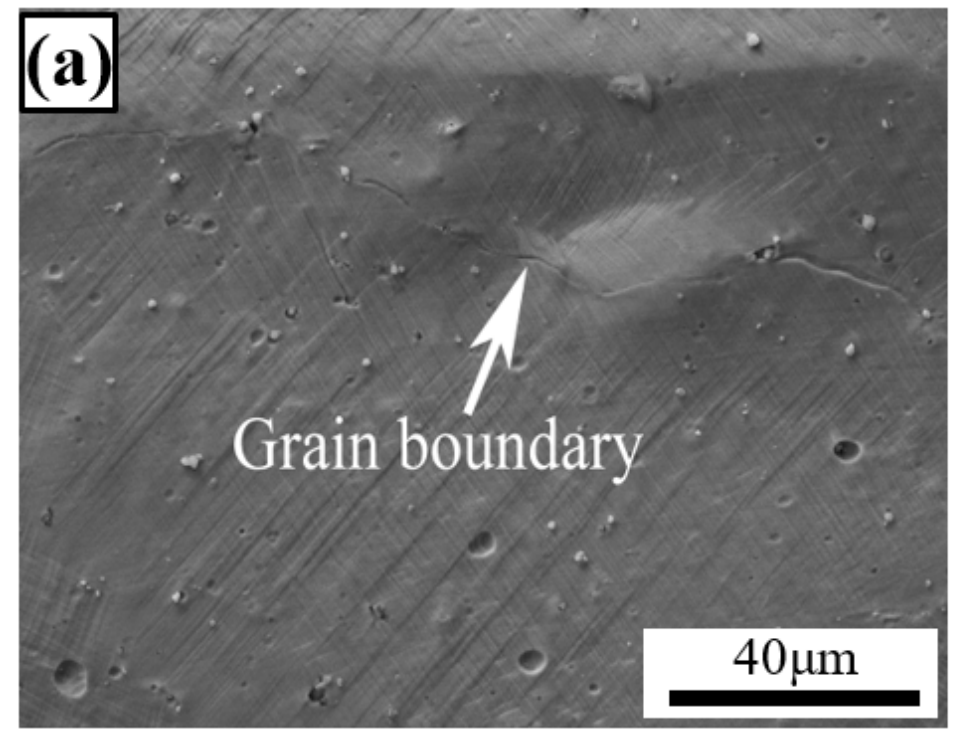

\section{(b)}

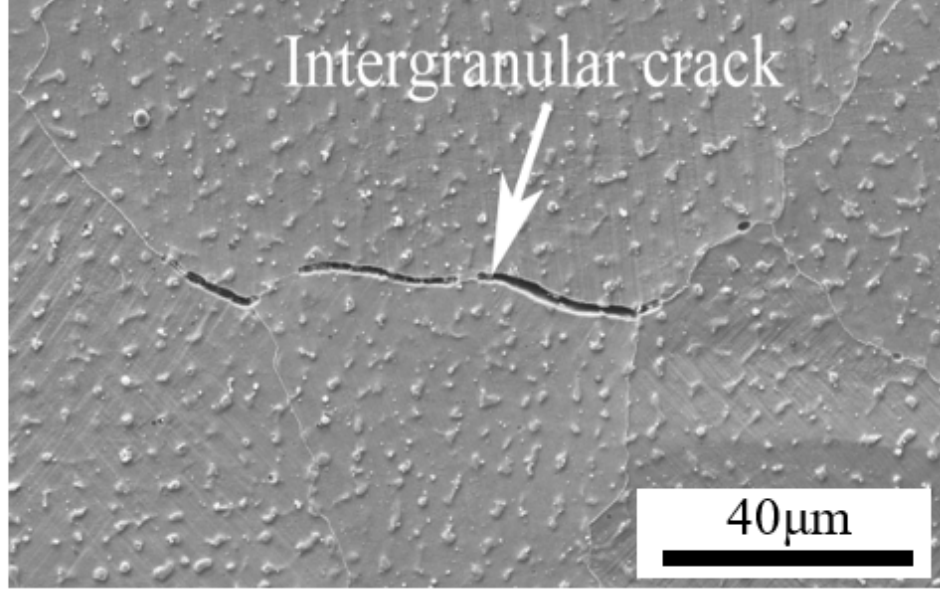

Figure 8

The effect of grain boundary on crack propagation in as-weld Alloy ENiCrFe-7 and (b) heat treatment one after $615^{\circ} \mathrm{C} / 48 \mathrm{~h}$.
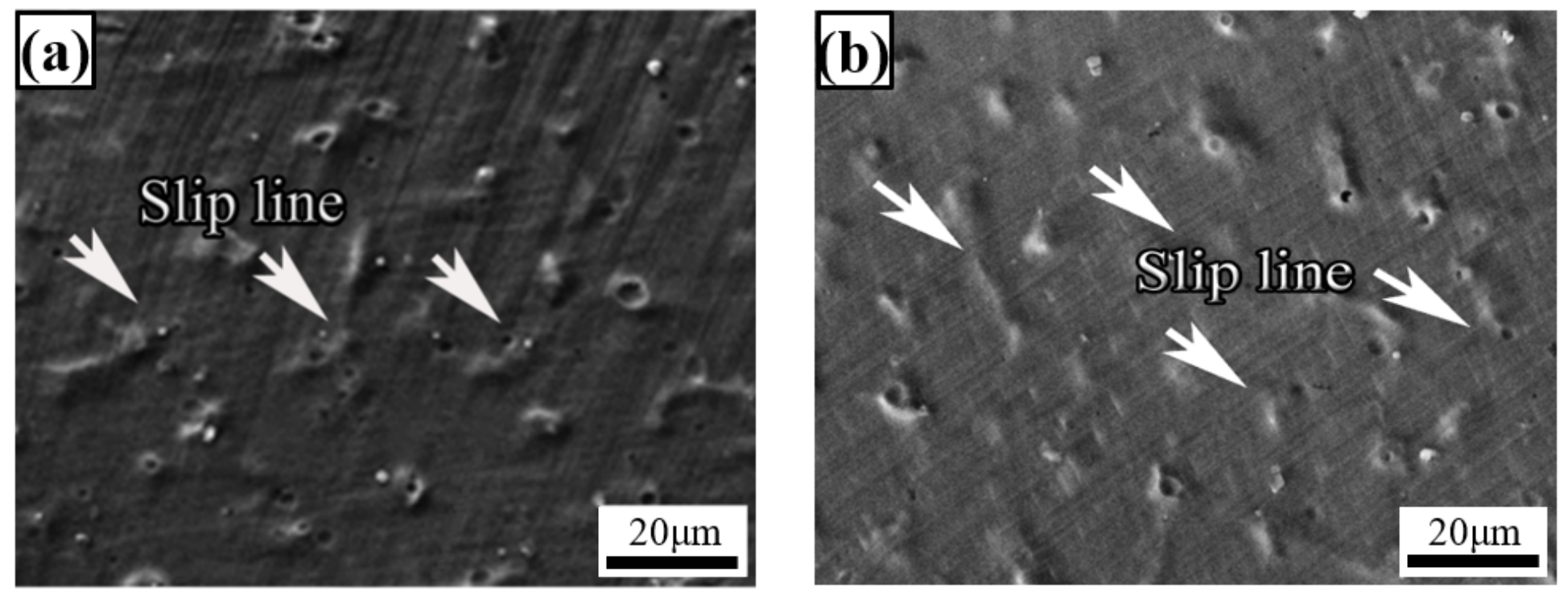

Figure 9

The effect of interdendrites on slip line in (a) as-weld ENiCrFe-7 and (b) heat treatment one after $615^{\circ} \mathrm{C} / 48 \mathrm{~h}$. 

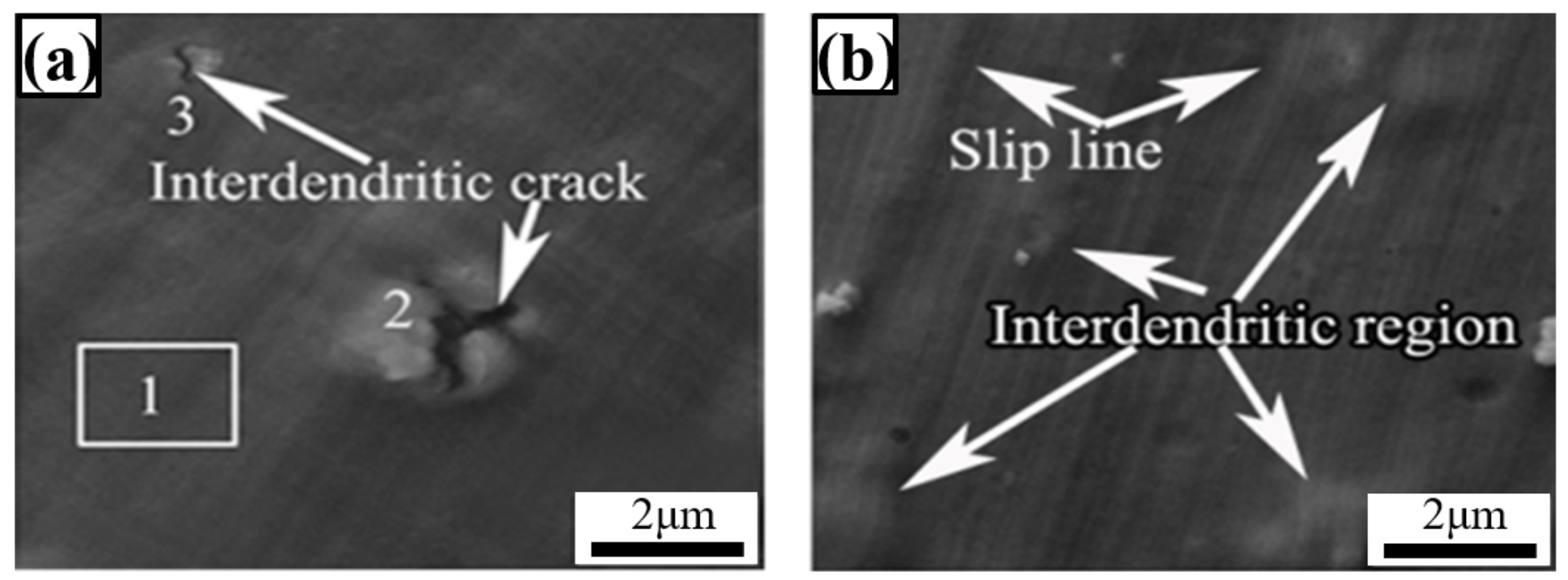

Figure 10

SEM images showing deformation of interdendrites in the as-weld Alloy ENiCrFe-7 and heat treatment one after $615^{\circ} \mathrm{C} / 48 \mathrm{~h}$.
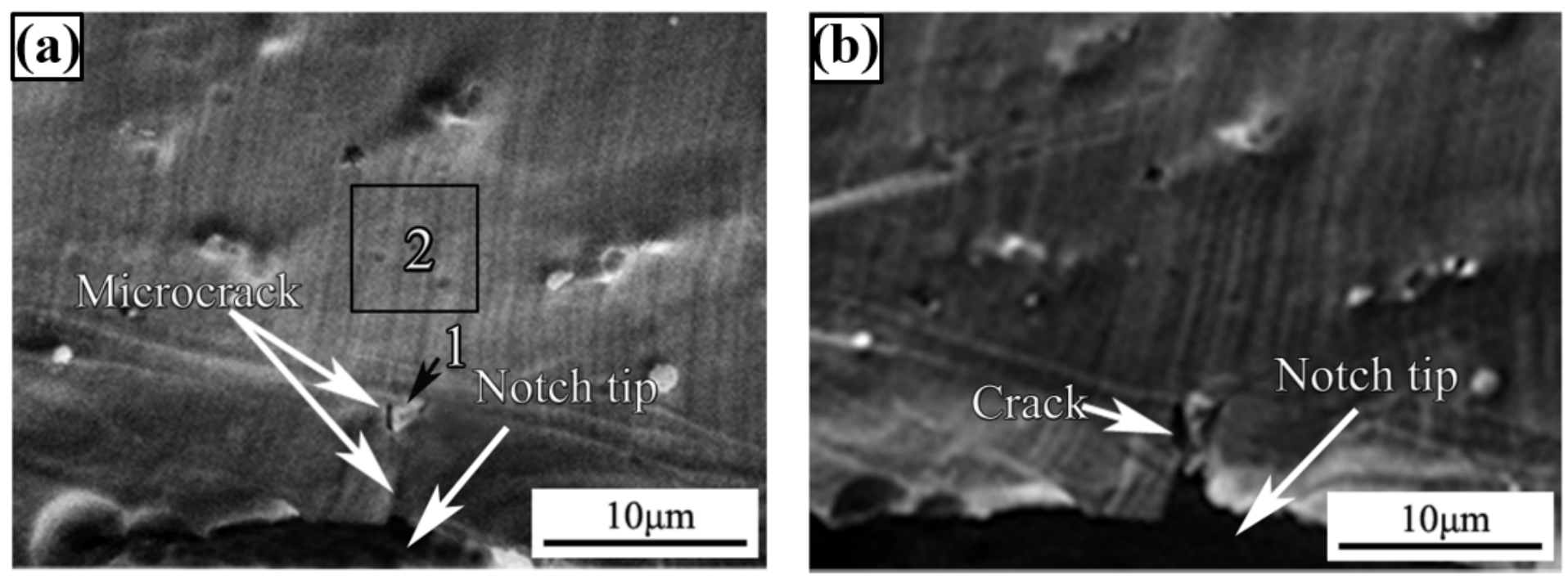

Figure 11

In-situ SEM observation near a notch tip of as-weld ENiCrFe-7; (a) an initiation of the mirocrack at the phase interface, (b) the coalescence of two microcracks into the main crack. 

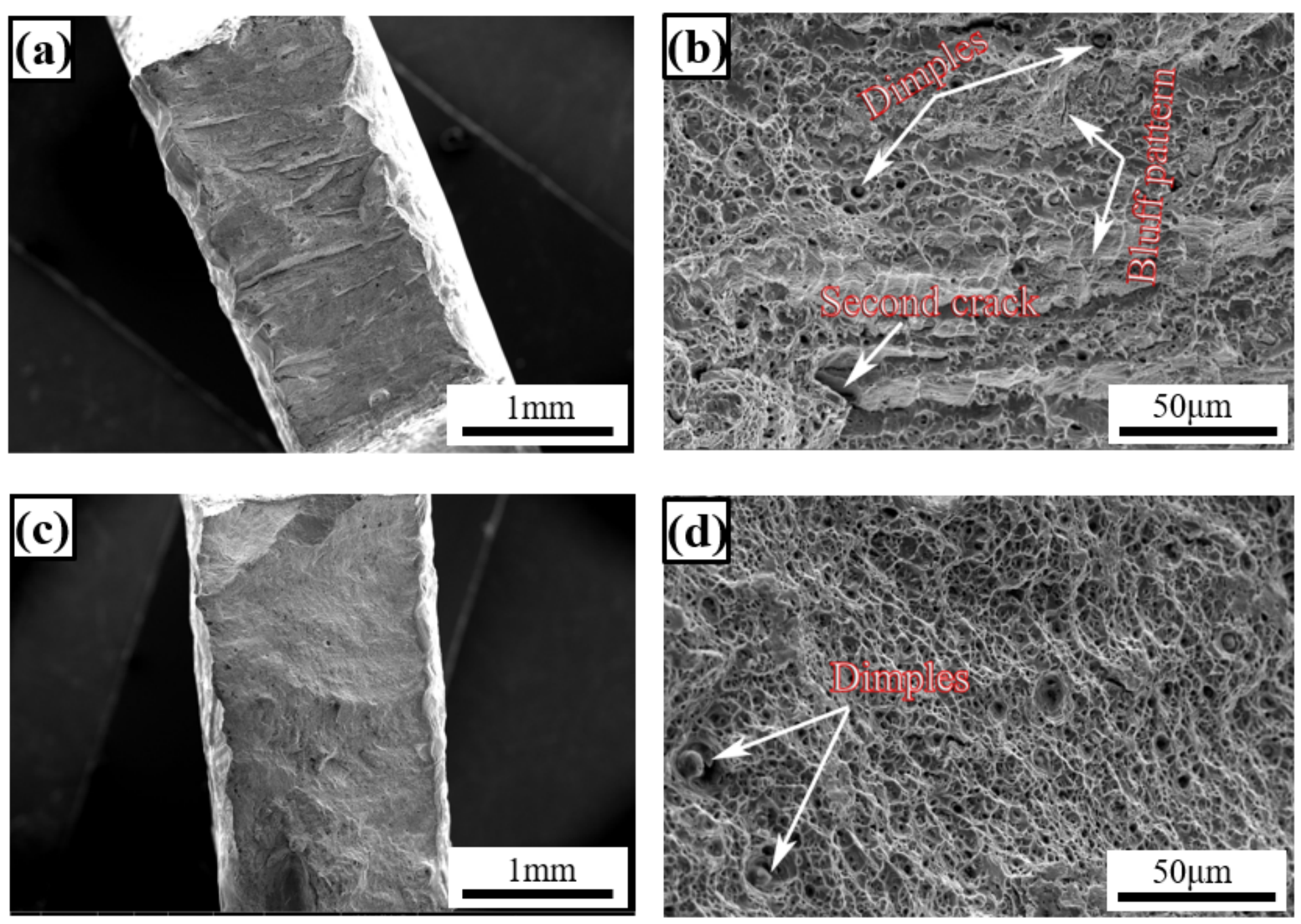

Figure 12

(a) and (c) The SEM images of fractured surfaces of as-weld ENiCrFe-7 and heat treatment one after

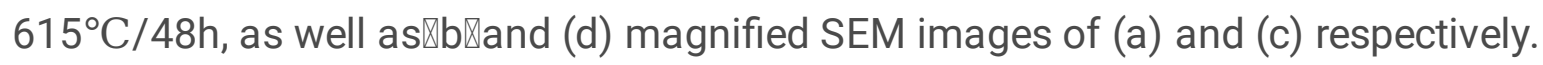




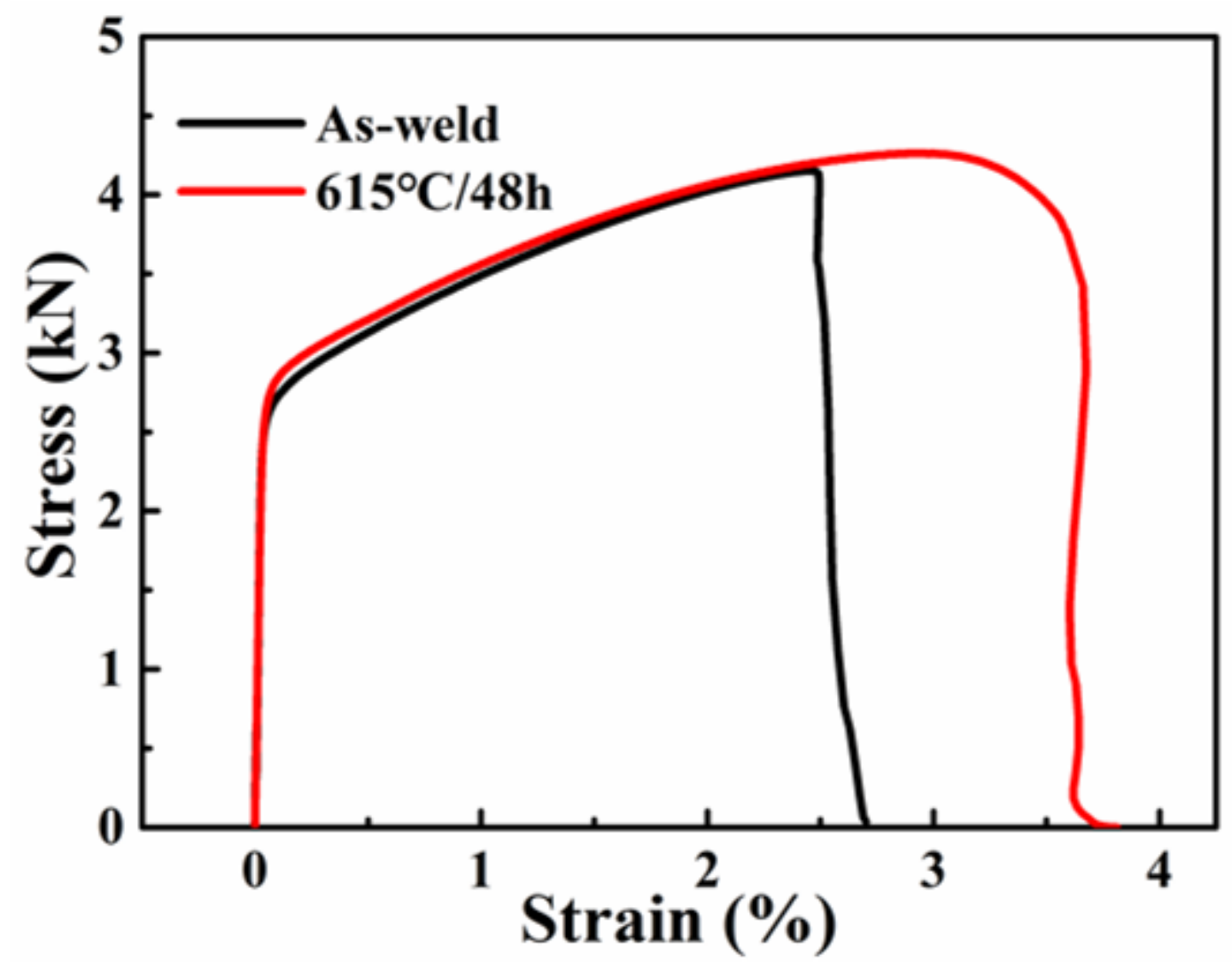

Figure 13

The stress-strain curve obtained of the as-weld Alloy ENiCrFe-7 and the heat treatment one after $615^{\circ} \mathrm{C} / 48 \mathrm{~h}$. 